\title{
Distribution of Spinal Neuronal Networks Controlling Forward and Backward Locomotion
}

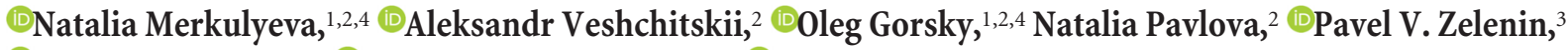

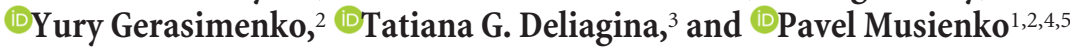 \\ ${ }^{1}$ Institute of Translational Biomedicine, St. Petersburg State University, 199034 St. Petersburg, Russia, ${ }^{2}$ Pavlov Institute of Physiology, 199034 St. \\ Petersburg, Russia, ${ }^{3}$ Department of Neuroscience, Karolinska Institute, SE-17177 Stockholm, Sweden, ${ }^{4}$ Russian Research Center of Radiology and Surgical \\ Technologies, Ministry of Healthcare of the RF, 197758 St. Petersburg, Russia, and ${ }^{5}$ St-Petersburg State Research Institute of Phthisiopulmonology, \\ Ministry of Healthcare of the RF, 191036 St. Petersburg, Russia
}

Higher vertebrates, including humans, are capable not only of forward (FW) locomotion but also of walking in other directions relative to the body axis [backward (BW), sideways, etc.]. Although the neural mechanisms responsible for controlling FW locomotion have been studied in considerable detail, the mechanisms controlling steps in other directions are mostly unknown. The aim of the present study was to investigate the distribution of spinal neuronal networks controlling FW and BW locomotion. First, we applied electrical epidural stimulation (ES) to different segments of the spinal cord from L2 to S2 to reveal zones triggering FW and BW locomotion in decerebrate cats of either sex. Second, to determine the location of spinal neurons activated during FW and BW locomotion, we used c-Fos immunostaining. We found that the neuronal networks responsible for FW locomotion were distributed broadly in the lumbosacral spinal cord and could be activated by ES of any segment from L3 to S2. By contrast, networks generating BW locomotion were activated by ES of a limited zone from the caudal part of L5 to the caudal part of L7. In the intermediate part of the gray matter within this zone, a significantly higher number of c-Fos-positive interneurons was revealed in BW-stepping cats compared with FW-stepping cats. We suggest that this region of the spinal cord contains the network that determines the BW direction of locomotion.

Key words: backward and forward walking; c-Fos; decerebrate cat; locomotor networks

Significance Statement

Sequential and single steps in various directions relative to the body axis [forward (FW), backward (BW), sideways, etc.] are used during locomotion and to correct for perturbations, respectively. The mechanisms controlling step direction are unknown. In the present study, for the first time we compared the distributions of spinal neuronal networks controlling FW and BW locomotion. Using a marker to visualize active neurons, we demonstrated that in the intermediate part of the gray matter within L6 and L7 spinal segments, significantly more neurons were activated during BW locomotion than during FW locomotion. We suggest that the network determining the BW direction of stepping is located in this area.

\section{Introduction}

Most bipeds and quadrupeds, in addition to forward (FW) walking, are also capable of backward (BW) and sideways walking (Stein et al., 1986; Buford and Smith, 1990; Rossignol, 1996; Zele-

\footnotetext{
Received Oct. 12, 2017; revised March 28, 2018; accepted April 6, 2018.

Author contributions: N.M., and P.M. designed research; N.M., A.V., and P.M. performed research;0.G., N.P., and Y.G. contributed unpublished reagents/analytic tools; N.M., A.V., O.G., P.V.Z., T.G.D., and P.M. analyzed data; N.M., P.V.Z., T.G.D., and P.M. wrote the paper.

This work was supported by the Russian Foundation for Basic Research (RFBR Grant 16-04-01791 to N.M. and RFBR Grant 17-04-01822 to P.M.), Grant of President of Russian Federation (MD-1018.2017.7), and by Russian Science Foundation (RSF Grant 14-15-00788 for physiological data analysis to P.M.); by Grant from NIH (R01 NS100928) to T.G.D. and P.M.; by Grants from Swedish Research Council to T.G.D. (11554 and 2017-02944) and to P.V.Z. (21076). We thank Medynja Kutueva for technical help assisting during the surgeries, experiments, and care of the cats; Vsevolod Lyakhovetskii for data analysis; and Dr. J. Sall for valuable comments on the paper.

The authors declare no competing financial interests.
}

nin et al., 2011). Single steps (corrective steps) in other directions are also used for postural corrections during locomotion and during standing (Beloozerova et al., 2003; Karayannidou et al., 2009; Musienko et al., 2014; Hsu et al., 2017).

The neural mechanisms controlling FW stepping were intensively studied during the past few decades. In vertebrates, basic nervous mechanisms controlling FW locomotion are located at the spinal-brainstem-cerebellum level. FW-stepping movements of an individual limb are generated by spinal neuronal networks. Sensory feedback from the limb affects these networks both di-

Correspondence should be addressed to Dr. Pavel Musienko, Institute of Translational Biomedicine, St. Petersburg State University, 199034 St. Petersburg, Russia. E-mail: pol-spb@mail.ru.

DOI:10.1523/JNEUROSCI.2951-17.2018

Copyright $\odot 2018$ the authors $\quad 0270-6474 / 18 / 384695-13 \$ 15.00 / 0$ 
rectly and through supraspinal systems, thus adapting their activity to different behavioral tasks and environmental conditions (for review, Sherrington, 1906; Grillner, 1975; Grillner and Zangger, 1979; Arshavsky et al., 1986; Orlovsky et al., 1999; Rossignol et al., 2006). It was demonstrated that the mesencephalic locomotor region (MLR; Shik and Orlovsky, 1976) is a command center initiating exclusively FW locomotion (Musienko et al., 2012). The spinal network [central pattern generator (CPG)] can generate stepping-like motor output in the absence of movementrelated afferent signals from the limbs (Grillner and Zanger, 1984; Kiehn, 2006). One of the hypotheses is that the locomotor CPG consists of two parts, the rhythm-generating network and the network responsible for the formation of the locomotor pattern of motoneuronal activity (two-layer model; Kiehn, 2006; McCrea and Rybak, 2008). It was demonstrated that in rodents and cats, the leading rhythm-generating networks reside in the rostral and midlumbar segments, respectively (Cazalets et al., 1995; Kjaerulff and Kiehn, 1996; Rossignol et al., 2002; Langlet et al., 2005).

Although the neural mechanisms responsible for the control of FW locomotion have been studied in considerable detail, knowledge about the neural mechanisms for generating steps in other directions is scarce. Comparative analysis of kinematics and electromyographic (EMG) patterns of FW and BW stepping in intact cats revealed similar basic hindlimb flexor-extensor synergies and led to the proposal that they are generated by the same spinal networks. Specific timing and recruitment levels of individual hindlimb muscles characteristic of a particular direction of walking are a result of integration with specific supraspinal signals and movement-dependent sensory feedback (Buford and Smith, 1990; Buford et al., 1990; Perell et al., 1993; Pratt et al., 1996).

A previous study showed that electrical epidural stimulation (ES) of the spinal cord can evoke not only FW but also BW locomotion (Musienko et al., 2007) in the decerebrate cat. Recently, we demonstrated that during stimulation of certain sites of the spinal cord, the direction of locomotion is determined by the direction of the treadmill belt movement, and if the treadmill is stopped, in-place stepping is observed (Musienko et al., 2012). It was suggested that the locomotor system includes two principal mechanisms, one generating a vertical component of step (limb elevation and lowering) and the other generating a horizontal component (limb transfer from one extreme point to the other). The latter includes networks generating the horizontal component of steps in different directions.

The first aim of the present study was to compare the effectiveness of ES stimulation of different segments of the lumbosacral enlargement for initiation of FW and BW locomotion. We found that FW locomotion can be evoked by ES of any segment from L3 to S2. By contrast, BW locomotion can only be evoked by ES of a limited zone from the caudal part of L5 to the caudal part of L7. We proposed that the network determining the BW direction of stepping is located in this zone. The second aim of the present study was to compare the distribution of spinal neuronal networks controlling FW and BW locomotion. For this purpose, we used the expression of the immediate early gene $c$-fos as a marker of neuronal activity to visualize active networks (for review, Sagar et al., 1988; Dragunow and Faull, 1989; Morgan and Curran, 1989).

\section{Materials and Methods}

Subjects. Experiments were performed on 19 adult cats of either sex (weighing 2.5-3.5 kg). All procedures were conducted in accordance with a protocol approved by the Animal Care Committee of the Pavlov Institute of Physiology, St. Petersburg, Russia, and followed the European Community Council Directive (2010/63EU) and the guidelines of the National Institute of Health Guide for the Care and Use of Laboratory Animals.

Surgical procedures. The cats were anesthetized deeply with isoflurane $(2-4 \%)$ delivered in $\mathrm{O}_{2}$. The level of anesthesia was monitored by applying pressure to a paw (to detect limb withdrawal), as well as by checking the size and reactivity of pupils. The trachea was cannulated and carotid arteries were ligated. The animals were decerebrated at the precollicularpostmammillary level. A laminectomy was performed in the lumbar area. To ensure that in our experiments normal EMG locomotor BW and FW patterns were generated (with bilateral alternation and reciprocity between antagonist muscles), antagonists of the ankle joint were recorded. For this purpose, bipolar EMG electrodes $(0.2 \mathrm{~mm}$ flexible stainless steel Teflon-insulated wires) were implanted bilaterally into $\mathrm{m}$. gastrocnemius lateralis (LG; ankle extensor), m. tibialis anterior (TA; ankle flexor) as described previously (Gerasimenko et al., 2009). Anesthesia was discontinued after the surgical procedures, and the experiments were started 2-3 h thereafter. During the experiment, the rectal temperature, electrocardiography, and breathing rate of the animal were continuously monitored. They were kept at $37 \pm 0.5^{\circ} \mathrm{C}, 110-140$ beats/min, and $20-40$ breaths/min, respectively.

Experimental design and analysis of electrophysiological data. The experimental design is shown in Figure 1. The head of the decerebrate animal, the vertebral column, and the pelvis were fixed in a rigid frame (Fig. 1A). The hindlimbs were positioned on the treadmill. The distance between the treadmill belt and the fixed pelvis was $21-25 \mathrm{~cm}$ (depending on the animal's size), which determined a limb configuration similar to that observed in the intact cat in the middle of stance during walking. In the cat decerebrated at the precollicular-postmammillary level, spontaneously initiated episodes of locomotion are absent. Locomotion was evoked by electrical ES of the spinal cord. This method is widely used to trigger locomotor circuitry in different animal models (Iwahara et al., 1992; Barthélemy et al., 2007; Courtine et al., 2009) and in humans (Dimitrijevic et al., 1998; Shapkov and Shapkova, 1998). To evoke locomotion by ES, a ball electrode $(d=0.5 \mathrm{~mm})$ was positioned on the dura mater of the spinal cord dorsal surface (Fig. 1A, ES) at different rostrocaudal levels (from L2 to S2). In all tested cats except one (Bw1), it was positioned on the midline (Fig. $2 A$ ). We used the following parameters of stimulation: frequency, $5 \mathrm{~Hz}$; pulse duration, $0.2-0.5 \mathrm{~ms}$; current, $80-$ $500 \mu \mathrm{A}$. The stimulation started in $2-3 \mathrm{~s}$ after onset of the treadmill belt motion. To evoke FW and BW locomotion, BW and FW motion of the treadmill belt (in relation to the cat) was used, respectively (Musienko et al., 2012).

To test the capacity of different spinal segments to evoke BW and FW locomotion in response to ES, 12 cats were used. The segments subjected to ES in individual cats are shown in Figure $3 A$. One can see that L2 and L 3 were stimulated in 3 cats; L4, in 7 cats; L5, in 12 cats; L6, in 10 cats; L7, in 8 cats; S1, in 5 cats; and S2, in 3 cats. To define the exact location of ES points within the corresponding spinal segments, a thorough dissection of the spinal cord was performed at the end of each experiment.

To characterize kinematics of locomotor movements, reflective markers were placed on the iliac crest, femoral head, lateral condyle of the femur, lateral malleolus, fifth metatarsal joint, and the side view of the walking cat (Fig. $1 B$ ) was video recorded ( 25 frames/s). In addition, we recorded the anterior-posterior (A-P) limb movements (by means of 2 mechanical sensors, one of which, Limb-R, is shown in Fig. 1A) synchronized with EMG and video recordings.

The signals from the EMG electrodes and from the position sensors were amplified (bandwidth $30-500 \mathrm{~Hz}$ ), digitized at $2 \mathrm{kHz}$, and saved to a computer disk.

To compare kinematics of locomotor movements evoked by ES of different spinal segments, the video recordings were analyzed frame-byframe. Angles at the hip, knee, and ankle joints were calculated at the moment when the limb was maximally flexed during the swing phase (Fig. $1 D$, swing angles) and at the moment when it was maximally extended in the stance phase (Fig. $1 D$, stance angles).

To characterize the stability of locomotor movements performed by an individual limb, the autocorrelation analysis of the time series of potentiometer signals (reflecting A-P movements of individual limb) was used. The autocorrelation was estimated with the help of the self- 

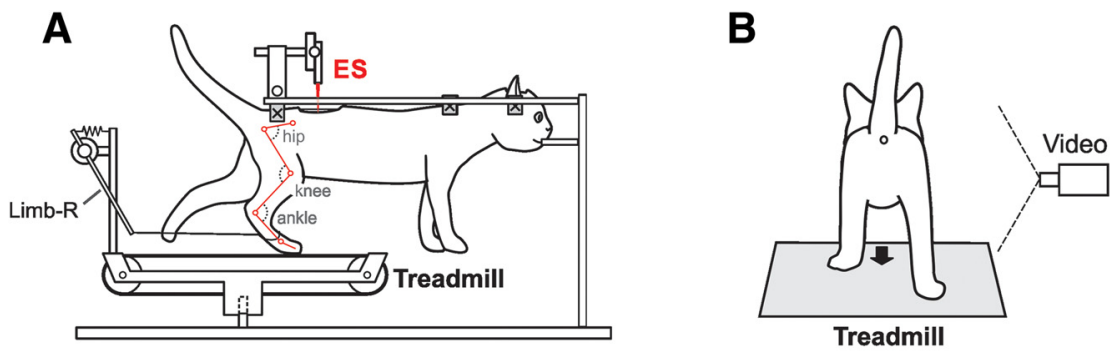

C

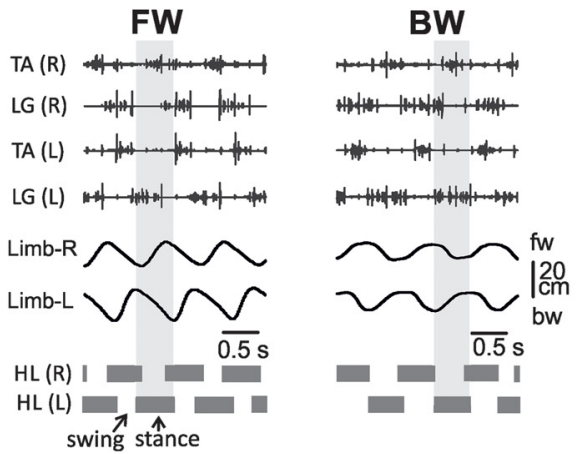

D

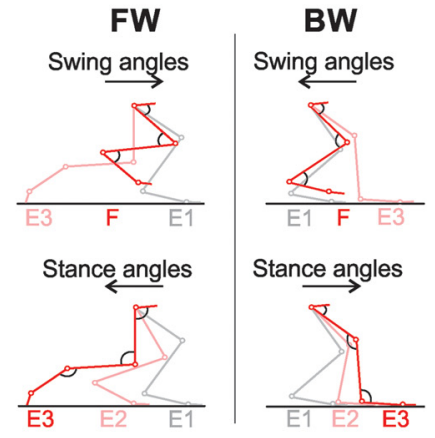

Figure 1. Experimental design. $A$, The head, vertebral column and pelvis of a decerebrate cat were fixed in a rigid frame (points of fixation are indicated by X). The hindlimbs were positioned on the treadmill. Walking of the hindlimbs was evoked by electrical ES of the spinal cord. A-P movements of each limb were recorded by a sensor (only the right sensor, Limb-R, is shown). To evoke FW and BW locomotion, during ES, the treadmill belt was moved backward and forward, respectively, in relation to the cat. Red circles are reflective markers attached to the skin projections of the main hindlimb joints. $\boldsymbol{B}$, The side view of the walking cat was recorded with a video camera (Video). C, Examples of FW and BW locomotion evoked by ES of the L5 segment. Limb-R and Limb-L, movements of the right and left hindlimbs, respectively. EMGs from right (R) and left (L) TA and LG. HL(R) and HL(L), structure of locomotor cycles of the right and left limbs, respectively. D, Hindlimb configuration at different moments of the swing and stance during FW and BW locomotion. E1, E2, E3, and F: end of the swing-beginning of stance, stance, end of the stance- beginning of the swing and swing, respectively. Configurations corresponding to the shortest limb length during the swing and the longest limb length during the stance (at E3) are indicated in red. Black horizontal arrows indicate the direction of the limb movement during the stance and swing of FW and BW locomotion.

similarity coefficient (the peak amplitude of the autocorrelation function; Kim et al., 2007). To reveal asymmetry in locomotor movements performed by the left and right hindlimbs (i.e., a difference in the paw excursion of the left and right limbs), the coefficient of asymmetry $(K)$ was calculated as $K=2 \times\left|S_{\text {left }}-S_{\text {right }}\right| /\left(S_{\text {left }}+S_{\text {right }}\right)$, where $S_{\text {left }}$ and $S_{\text {right }}$ are the paw excursions of the left and right limb, respectively. The paw excursion was calculated as the distance between the position of the paw at the beginning and at the end of the stance phase.

Experimental protocol for c-Fos labeling of neurons of spinal locomotor networks and analysis of morphological data. Seven cats were used for c-Fos labeling of neurons of spinal locomotor networks. In $2 \mathrm{~h}$ after surgery, during which the decerebrate cat was left to recover from anesthesia, the capacity of the cat to perform FW or/and BW locomotion in response to ES of different spinal segments was briefly (during 3-5 min) tested as described above. Based on this test, the "optimal" strength of ES (see Results) and the optimal position of the ES electrode to evoke FW or BW locomotion were determined. To ensure stable locomotion during the $1.5-2 \mathrm{~h}$ required for c-Fos labeling, a twofold increase of the optimal strength of ES was used (average $275 \pm 39 \mu \mathrm{A}$ ).

Three cats (Fw1, Fw2, and Fw3) were used for c-Fos labeling of neurons activated during FW locomotion evoked by ES applied to the rostral part of L5, between L6 and L7, and to the middle of L7, respectively (Fig. $2 A$ ). Three other cats (Bw1, Bw2, and Bw3) were used for c-Fos labeling of neurons activated during BW locomotion evoked by ES applied to the middle of L7, to the rostral part of L6 and to the border between L5 and L6, respectively (Fig. 2A). The cats performed 1-2 min of locomotion alternated with 2-4 min of rest during 1.5-2 h (Jasmin et al., 1994; Ahn et al., 2006). In addition, to reveal neurons with early $c$-fos expression (Ahn et al., 2006) and to test the specificity of c-Fos immunostaining under our experimental conditions, one cat (sFW) performed FW locomotion for $30 \mathrm{~min}$ only. In this cat ES was applied to each of L5-L7 segments for $10 \mathrm{~min}$.

Perfusion and dissection. At the end of experiments, animals were deeply anesthetized with isoflurane $(5 \%)$, and then perfused transcardially with $0.9 \% \mathrm{NaCl}(2.0 \mathrm{~L})$ in $0.1 \mathrm{M}$ PBS at $\mathrm{pH}$ 7.4 , followed by $4 \%$ paraformaldehyde $(2.0 \mathrm{~L})$ in $0.1 \mathrm{M}$ PBS, $\mathrm{pH}$ 7.4. Then a detailed dissection of vertebrae, roots, and spinal cord was performed to determine the exact level of the spinal cord stimulation, including laminectomies of spinal segments used for subsequent immunohistochemical analysis. To define the exact positon of the epidural electrode, an area below the electrode was marked by a black dot just after stimulation. After removing the dura matter, this mark was carefully transferred to the pia matter. Before the dura matter was removed, a photo of the dot was made showing the dot's position in relation to the blood vessels. This photo was used to ensure a correct position of the dot on the pia matter. The lumbosacral spinal cord was removed from the spine and stored in 20 and $30 \%$ sucrose until it sank. The lumbosacral cord was divided into segments based upon the grouping of the dorsal rootlets. The $\mathrm{L} 4-\mathrm{S} 1$ segments were cut on a freezing microtome into $50 \mu \mathrm{m}$ transverse sections. Sections were collected in $0.1 \mathrm{M}$ PBS, $\mathrm{pH}$ 7.4. Approximately equally spaced sections were processed for the immunohistochemical protocol to label c-Fos nuclei in spinal cord gray matter ( 5 sections per segment).

Immunohistochemical staining. Sections were processed as free-floating. To unmask any antigens, sections were processed in $1 \% \mathrm{NaBH}_{4}$ for $30 \mathrm{~min}$; endogenous peroxidase activity was blocked in $0.3 \% \mathrm{H}_{2} \mathrm{O}_{2}$ for $15 \mathrm{~min}$. To block nonspecific staining, sections were incubated for $1 \mathrm{~h}$ in $10 \%$ normal goat serum (NGS; Vector Laboratories). Triton $\mathrm{X}-100(0.3 \%)$ was added for this and subsequent incubations to enhance antibody penetration. Between all procedures, the sections were washed $3 \times 5 \mathrm{~min}$ in $0.01 \mathrm{M}$ PBS. The sections were incubated for $70 \mathrm{~h}$ at $+4^{\circ} \mathrm{C}$ in polyclonal rabbit primary antibodies to c-Fos (PC38-100U; Oncogene Research Products, Calbiochem; PRID:AB_2106755), generated against a synthetic peptide corresponding to amino acids 4-17 of human c-Fos and recognizing the $\sim 55 \mathrm{kDa}$-Fos and $\sim 62 \mathrm{kDa} \mathrm{v}$-Fos proteins but not a 39,000 c-Jun protein, in 1:10,000 dilution). In previous publications using the same antibody, specificity to neuronal nuclei in the cat spinal cord was demonstrated (Noga et al., 2009). Then, the sections were incubated in secondary antibodies (biotinylated goat anti-rabbit IgG; BA1000, Vector Laboratories; PRID:AB_2313606; 1:600 dilution) for $1 \mathrm{~d}$, followed by incubation in avidin-biotin horseradish-peroxidase complex (ABC Elite system, Vector Laboratories) for $1 \mathrm{~h}$. The peroxidase reaction was visualized with a mixture of diaminobenzidine (DAB), $\mathrm{NiCl}$ and $0.03 \% \mathrm{H}_{2} \mathrm{O}_{2}$ (Vectastain DAB kit, Vector Laboratories). After washing in distilled water, sections were mounted, dehydrated, cleared, and placed under coverslips. As a control for antibody specificity, sections were processed in NGS alone or in solutions containing only primary or only secondary antibodies. No staining was observed in this case.

Analysis. Images (Fig. 2A) were acquired with a microscope (Olympus Corporation, $10 \times$ objective) equipped with a photo camera (Nikon Corporation). c-Fos-Positive (FOS + ) nuclei were often pale on photos (Fig. $2 B$, inset box 2, black arrows) because they were located deep in the $50 \mu \mathrm{m}$ section and thus out of camera focus; therefore, nuclei count was always done under microscope control. Five sections for each of the L4-S1 spinal segments were selected for analysis in individual cats, and FOS + nu- 
clei were marked by dots on their images. These images were then processed with free software from Fiji (Schindelin et al., 2012; PRID: SCR_002285), adjusting the brightness, contrast, and sharpness to make contoured images. Then a "total section" of a particular segment was created (Fig. 2C). For this purpose, five images were superimposed using particular section features as landmarks, and averaged white/gray matter boundaries were outlined. FOS + nuclei marked by dots were blurred (Gauss blur, $d=125$ pixels) and, finally, a color-coded image was generated with Fiji tools to illustrate the FOS + nuclei density (Fig. 2C). For the images shown in Figure $5 A$, the green-to-red gradient corresponding to optical density is specific for each segment in each cat, and thus these images allow to compare qualitatively (but not quantitatively) the patterns of FOS + nuclei distribution in different segments of different cats.

For visualization of the general c-Fos labeling in a certain segment within each of two experimental group (Fw1, Fw2, Fw3, and Bw1, Bw2, Bw3), data from three "total sections" of a particular segment from individual animals of the FW or BW group were combined to visualize areas with the greatest FOS + nuclei density (see Fig. 5B).

Statistical analysis. All quantitative data in this study are presented as mean $\pm \mathrm{SE}$; unpaired $t$ - and $z$-tests were used to characterize the statistical significance when comparing different means. The significance level was set at $p<0.05$.

\section{Results}

Efficacy of ES of different lumbosacral segments to evoke $\mathrm{FW}$ and BW locomotion

To test the capacity of different spinal segments to trigger FW and BW locomotion in response to ES, first, the optimal strength of ES stimulation was determined for individual cats (Musienko et al., 2007, 2012). For this purpose, a stimulating electrode was placed on L5, and the minimal strength of ES sufficient to evoke stable FW locomotion (at least 10 steps with digitigrade paw placement) was determined. Then, ES with this optimal strength was applied to other segments (from L2 to S2) to test their capacity to evoke FW and BW locomotion. The value of the optimal strength of ES was within the range of $80-250 \mu \mathrm{A}$ in individual cats. The red line in Figure $3 C$ shows the mean \pm SE value of the optimal strength of ES for animals in which a particular segment was subjected to ES. If the optimal strength of ES was not efficient to initiate BW or FW stepping, the strength of ES was increased up to $300-500 \mu \mathrm{A}$ (Fig. $3 C$, gray line). However, we found that an increase in the strength of ES above the optimal value did not lead to the initiation of locomotion.

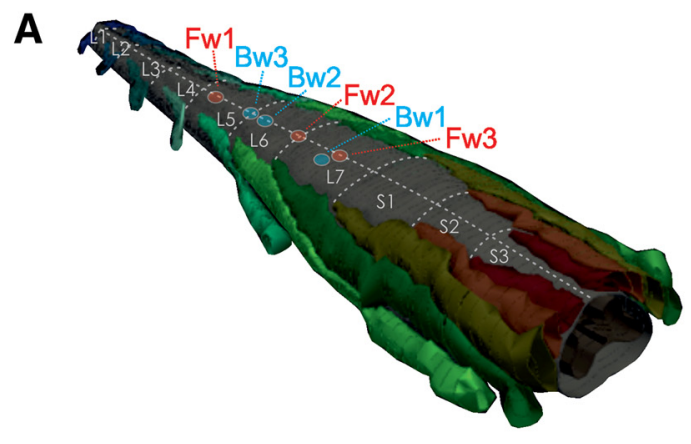

B

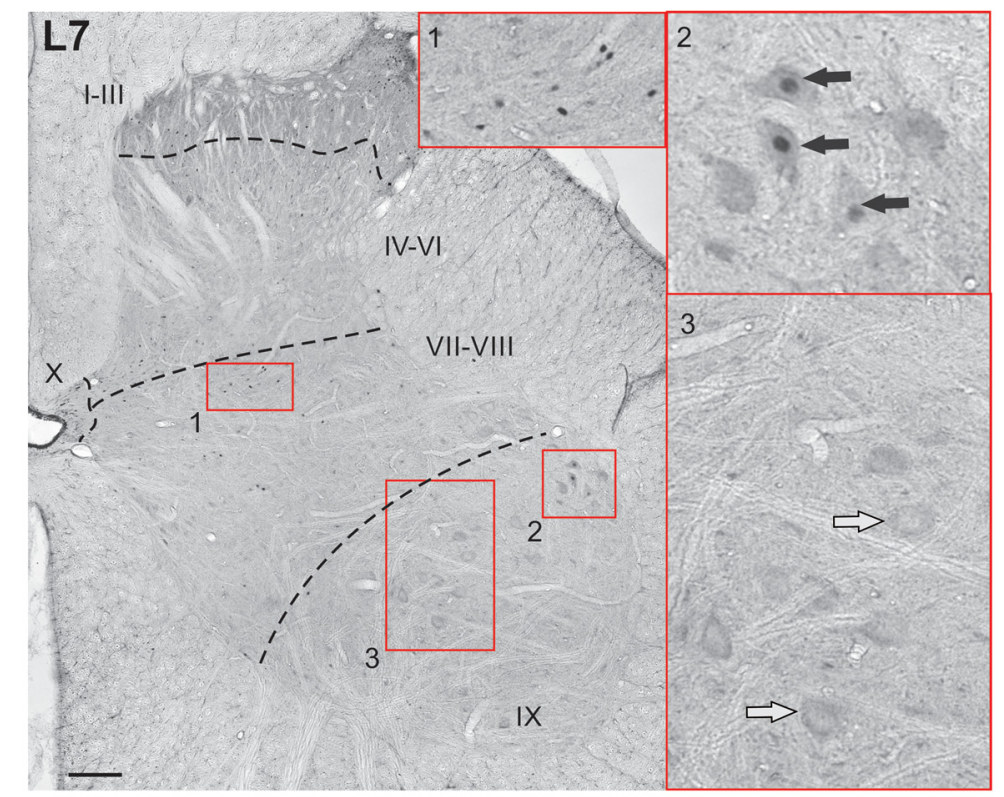

C
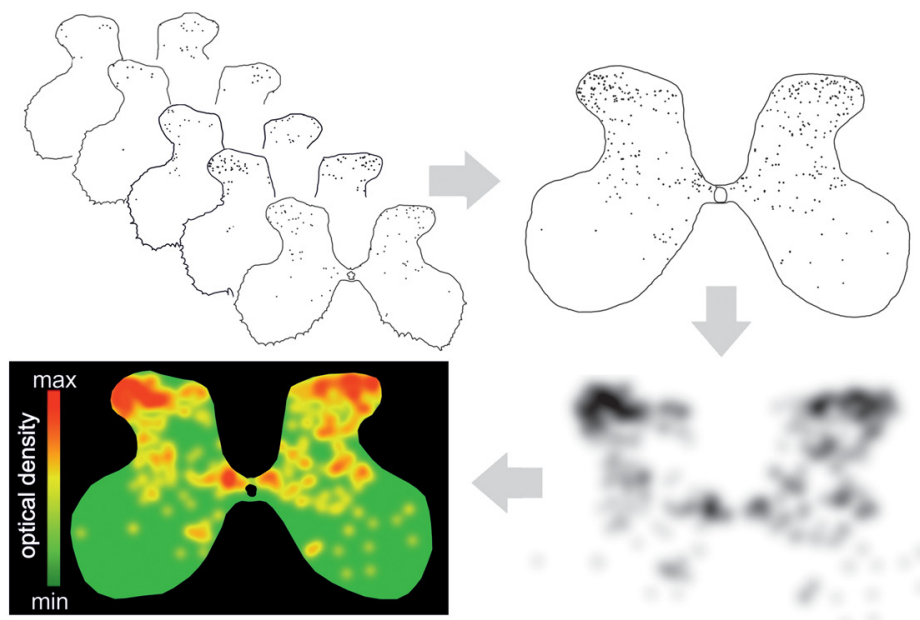

Figure 2. c-Fos Labeling of spinal neurons of locomotor networks and analysis of distribution of c-Fos-positive neurons. $A$, Sites of ES application for initiation of BW and FW locomotion in individual cats used for c-Fos labeling of spinal neurons. Fw1, Fw2, Fw3 and Bw1, Bw2, Bw3 are cats that performed FW and BW locomotion, respectively. B, Distribution of FOS + nuclei on a frontal section of $\mathrm{L} 7$ in the cat Fw2. Borders between Rexed laminae are indicated by interrupted lines. Rexed laminae were segregated on the basis of morphological criteria described by Rexed (1954). Right, Magnifications of the red boxed areas containing labeled interneuronal nuclei (box 1), motoneuronal nuclei marked by black arrows (box 2) and unlabeled motoneuronal nuclei marked by white arrows (box 3). Scale bar, $200 \mu \mathrm{m}$. C, Procedure for visualizing the density of the FOS + nuclei distributed over the cross section of a particular spinal segment (see Material and Methods). Bottom left, A color map of the density of FOS + nuclei. 
A

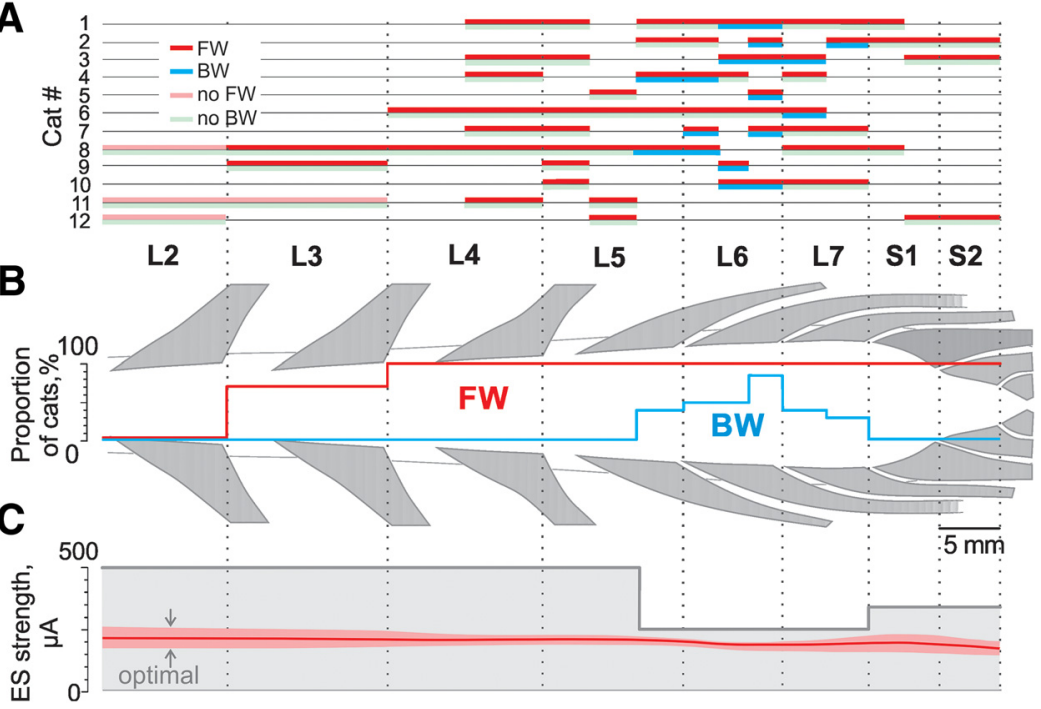

Figure 3. Efficacy of ES of different lumbosacral segments to evoke FW and BW locomotion. $\boldsymbol{A}$, Effects of ES observed in individual animals. Each horizontal line shows the results obtained in an individual animal. Thick lines indicate segments (or parts of the segments) subjected to ES, and their color encodes the effect of stimulation (red, FW stepping; blue, BW stepping; pink, absence of FW stepping; light green, absence of BW stepping). $\boldsymbol{B}$, Proportion of cats in which ES of a particular segment (or a part of the segment) evoked FW (red line) and BW (blue line) locomotion. C, The mean value of the optimal strength of ES for cats subjected to ES of a particular segment (or a part of the segment) is shown by the red line. The SE is indicated by the pink shading. The maximum strength of ES applied to a particular segment in an attempt to initiate FW or BW stepping is shown by a gray line.

activity [in LG (L) and LG (R), as well as in TA (L) and TA (R)] and reciprocity in the activity of LG and TA located within each limb. Similar EMG patterns during FW and BW locomotion were observed in all studied cats. They were similar to those observed in intact cats during FW and BW locomotion (Buford and Smith, 1990; Pratt et al., 1996).

\section{Differences in kinematics of locomotor movements evoked by ES of different lumbosacral segments}

We compared the kinematic characteristics of FW locomotor movements evoked by ES applied at three different rostrocaudal levels (at L4-L5, L6, and L7-S1). For this purpose, data obtained in four cats ( 3 , 4, 6 and 7; Fig. 3A) were used. Each of these cats was subjected to ES at all three rostrocaudal levels. Table 1 shows the mean \pm SE values of the hip, knee, and ankle joint angles at maximal flexion of the hindlimb during swing and at its maximal extension at the end of the stance during FW locomotion evoked by ES of L4-L5, L6, and L7-S1. One can see that

The results of testing the efficacy of ES of different lumbosacral segments to evoke FW and BW locomotion are summarized in Figure 3A. Each horizontal line in this figure shows the results obtained in an individual animal. Thick lines indicate segments (or parts of the segments) to which ES was applied, and their color indicates the effect of stimulation. One can see that ES of L2 was not able to initiate either FW or BW locomotion (Fig. 3A, L2, pink and light green thick lines, respectively).

ES applied to L3 evoked FW locomotion in 2 of 3 (67\%, Fig. $3 B$ ) tested cats (Fig. 3A, L3, red thick lines and pink thick line) but did not evoke BW locomotion in any of the 3 tested cats (Fig. $3 A$, L3, light green thick lines).

We found that ES applied at different rostrocaudal levels of segments L4, L5, L6, L7, S1, and S2 evoked FW locomotion in all tested animals (Fig. 3A, L4-S2, red thick lines). In contrast, ES of the same sites in L4, in the rostral and middle parts of L5, and in the rostral and caudal parts of S1 and in S2, which evoked FW locomotion, could not initiate BW locomotion in any of the tested animals (Fig. 3A, L4-L5, S1, S2, light green tick lines).

However, optimal ES stimulation applied within the region from the caudal part of L5 to L7 evoked BW stepping in a subset of the tested animals. The probability of evoking BW stepping gradually increased from the caudal part of L5 (success in $40 \%$ of tested cats) to L6 (success in 50, 67, and $86 \%$ of tested animals stimulated in the rostral, middle, and caudal parts of the segment, respectively) and then decreased in L7 (success in 29 and 20\% of tested animals stimulated in the rostral and caudal parts of the segment, respectively; Fig. $3 B$ ). As shown in Figure $3 A$, each cat had a specific region of the spinal cord where stimulation evoked BW stepping. That region occupied at most one segment length (on average, $71 \pm 10 \%$ of segment length, $N=10$ ). Changing the direction of the treadmill belt motion from BW to FW (Fig. 1A) resulted in switching from FW to BW locomotion at constant parameters of ES in this region. Figure $1 C$ shows an example of FW and BW locomotion evoked in an individual animal by ES of the same site in L5. One can see bilateral alternation of EMG swing angles and stance angles at all joints were significantly smaller during locomotion evoked by ES of L4-L5 than those during stepping evoked by ES of L7-S1. During locomotion evoked by ES of L6, these parameters had intermediate values. Thus, during FW stepping evoked by ES of rostral segments (L4L5), the limb configuration was more flexed during the locomotor cycle (suggesting predominance in activity of flexors) than that during stepping evoked by ES of caudal segments (L7-S1; suggesting predominance in activity of extensors). It was also found that though the paw excursion was similar at all three conditions (Fig. $4 B$ ), the mean value of the range over which hindlimb joint angles changed during the locomotor cycle (that is, a difference between Stance angle and Swing angle averaged over all hindlimb joints in all cats) was significantly larger during locomotion evoked by ES of L7-S1 than that observed during stepping initiated by ES of L4-L5 $\left(t_{(236)}=-5.44, p=6.8 \times\right.$ $10^{-8}$, unpaired $t$ test; Fig. $4 C$ ). The stability of locomotor movements of an individual hindlimb was rather high under all three conditions, although it was slightly lower when stepping was initiated by ES of L6 $\left(t_{(14)}=1.96, p=0.035\right.$, for L5 and L6 comparison, and $t_{(13)}=-3,43, p=0.002$, for L6 and L7 comparison, unpaired $t$ test; Fig. $4 D$ ). Finally, the mean value of the coefficient of asymmetry was very low under all three conditions, indicating similar step lengths for the left and right hindlimbs and thus suggesting symmetrical left-right hindlimb locomotor movements (Fig. 4E).

During BW locomotion, the limb performed movements in both swing and stance in direction opposite to that observed during FW locomotion. In the stance phase (Fig. 1D, BW, Stance angles), the foot moved from the extreme posterior position (E1) to the extreme anterior position (E3). In the swing phase (Fig. 1D, BW, Swing angles), the foot returned to the extreme posterior position (E1). It can be seen that the limb locomotor movements were performed in a much more rostral position in relation to the body compared with movements during FW walking (Fig. 1D, $\mathrm{BW}$ and FW, respectively). We found that the mean values for the 
Table 1. Basic kinematic characteristics of individual cats stepping FW ( \pm SE) evoked by ES applied at three different rostrocaudal levels (at L4-L5, L6, and L7-S1)

\begin{tabular}{|c|c|c|c|c|c|c|}
\hline Step phase & ES & Joint & Cat 1 & Cat 2 & Cat 3 & Cat 4 \\
\hline \multirow[t]{12}{*}{ Swing } & L4-L5 & Hip & $36.6 \pm 0.4$ & $32.2 \pm 0.3$ & $53.4 \pm 0.6$ & $32.8 \pm 0.9$ \\
\hline & L6 & & $43.5 \pm 0.2$ & $37.1 \pm 0.5$ & $57.5 \pm 1.0$ & $38.9 \pm 0.8$ \\
\hline & L7-S1 & & $41.5 \pm 0.6^{* * *}$ & $40.8 \pm 0.3^{* * *}$ & $61.4 \pm 1.0^{* * *}$ & $40.9 \pm 0.7^{* * *}$ \\
\hline & & & $\begin{array}{l}t_{(\mathrm{df}=15)}=-6.94 \\
p=2.4 \times 10^{-6}\end{array}$ & $\begin{array}{l}t_{(\mathrm{df}=17)}=-20.93 \\
p=7.1 \times 10^{-14}\end{array}$ & $\begin{array}{l}t_{(\mathrm{df}=15)}=-7.08 \\
p=1.86 \times 10^{-6}\end{array}$ & $\begin{array}{l}t_{(\mathrm{df}=17)}=-7.38 \\
p=5.4 \times 10^{-7}\end{array}$ \\
\hline & L4-L5 & Knee & $35.9 \pm 0.6$ & $36.4 \pm 1.1$ & $55.4 \pm 0.9$ & $37.9 \pm 0.4$ \\
\hline & L6 & & $38.8 \pm 0.9$ & $38.2 \pm 0.4$ & $56.1 \pm 0.3$ & $47 \pm 1.0$ \\
\hline & L7-S1 & & $40.3 \pm 0.5^{* * *}$ & $40.8 \pm 0.2^{* *}$ & $60.6 \pm 2.0^{*}$ & $50 \pm 1.4^{* * *}$ \\
\hline & & & $\begin{array}{l}t_{(\mathrm{df}=12)}=-3.50 \\
p=0.002\end{array}$ & $\begin{array}{l}t_{(\mathrm{df}=10)}=-4.13 \\
p=0.001\end{array}$ & $\begin{array}{l}t_{(\mathrm{df}=11)}=-2.45 \\
p=0.016\end{array}$ & $\begin{array}{l}t_{(\mathrm{df}=10)}=-8.31 \\
p=4.2 \times 10^{-6}\end{array}$ \\
\hline & L4-L5 & Ankle & $42.5 \pm 1.2$ & $44.7 \pm 1.0$ & $73.4 \pm 0.7$ & $34.6 \pm 0.4$ \\
\hline & L6 & & $58 \pm 1.4$ & $46.7 \pm 0.7$ & $76.3 \pm 1.8$ & $42.4 \pm 0.6$ \\
\hline & L7-S1 & & $45.6 \pm 1.1^{*}$ & $52.3 \pm 1.3^{* * *}$ & $82.7 \pm 1.5^{* * *}$ & $44.2 \pm 0.3^{* * *}$ \\
\hline & & & $\begin{array}{l}t_{(\mathrm{df}=11)}=-2.63 \\
p=0.012\end{array}$ & $\begin{array}{l}t_{(\mathrm{df}=10)}=-5.77 \\
p=9.0 \times 10^{-5}\end{array}$ & $\begin{array}{l}t_{(\mathrm{df}=13)}=-5.66 \\
p=3.9 \times 10^{-5}\end{array}$ & $\begin{array}{l}t_{(\mathrm{df}=17)}=-22.77 \\
p=1.8 \times 10^{-14}\end{array}$ \\
\hline \multirow[t]{12}{*}{ Stance } & L4-L5 & Hip & $85.7 \pm 0.4$ & $94.8 \pm 0.6$ & $102.1 \pm 0.8$ & $74.2 \pm 0.4$ \\
\hline & L6 & & $93.7 \pm 0.7$ & $105.4 \pm 0.8$ & $112.3 \pm 1.0$ & $80.1 \pm 0.7$ \\
\hline & L7-S1 & & $100.4 \pm 0.3^{* * *}$ & $122.3 \pm 1.0^{* * *}$ & $118.7 \pm 0.8^{* * *}$ & $107.5 \pm 1.2^{* * *}$ \\
\hline & & & $\begin{array}{l}t_{(\mathrm{df}=14)}=-23.08 \\
p=7.6 \times 10^{-13}\end{array}$ & $\begin{array}{l}t_{(\mathrm{df}=18)}=-17.85 \\
p=3.4 \times 10^{-13}\end{array}$ & $\begin{array}{l}t_{(\mathrm{df}=17)}=-13.55 \\
p=7.7 \times 10^{-11}\end{array}$ & $\begin{array}{l}t_{(\mathrm{df}=11)}=-26.5 \\
p=1.3 \times 10^{-11}\end{array}$ \\
\hline & L4-L5 & Knee & $87 \pm 0.4$ & $96.4 \pm 0.3$ & $107.9 \pm 0.7$ & $64.8 \pm 0.3$ \\
\hline & L6 & & $92.7 \pm 1.7$ & $117.3 \pm 0.5$ & $120.1 \pm 0.7$ & $80.9 \pm 0.5$ \\
\hline & L7-S1 & & $105.2 \pm 0.7^{* * *}$ & $126.2 \pm 0.4^{* * *}$ & $121.8 \pm 0.8^{* * *}$ & $104.9 \pm 0.5^{* * *}$ \\
\hline & & & $\begin{array}{l}t_{(\mathrm{df}=14)}=-22.36 \\
p=1.2 \times 10^{-12}\end{array}$ & $\begin{array}{l}t_{(\mathrm{df}=16)}=-38.47 \\
p=1.7 \times 10^{-17}\end{array}$ & $\begin{array}{l}t_{(\mathrm{df}=18)}=-12.43 \\
p=1.4 \times 10^{-10}\end{array}$ & $\begin{array}{l}t_{(\mathrm{df}=17)}=-58.35 \\
p=2.5 \times 10^{-21}\end{array}$ \\
\hline & L4-L5 & Ankle & $133.2 \pm 1.2$ & $155.3 \pm 2.7$ & $124 \pm 0.6$ & $122 \pm 0.5$ \\
\hline & L6 & & $138.7 \pm 1.5$ & $172 \pm 0.7$ & $135.6 \pm 1.0$ & $126 \pm 1.4$ \\
\hline & L7-S1 & & $138.2 \pm 0.4^{* * *}$ & $179.4 \pm 2.7^{* * *}$ & $143.9 \pm 0.8^{* * *}$ & $134.7 \pm 0.7^{* * *}$ \\
\hline & & & $\begin{array}{l}t_{(\mathrm{df}=11)}=-3.4 \\
p=0.001\end{array}$ & $\begin{array}{l}t_{(\mathrm{df}=9)}=-9.05 \\
p=4.1 \times 10^{-6}\end{array}$ & $\begin{array}{l}t_{(\mathrm{df}=17)}=-20.73 \\
p=8.3 \times 10^{-14}\end{array}$ & $\begin{array}{l}t_{(\mathrm{df}=16)}=-15.05 \\
p=3.7 \times 10^{-11}\end{array}$ \\
\hline
\end{tabular}

Asterisks mark the significant differences in parameters between stepping evoked by stimulation of segments $\mathrm{L} 4-\mathrm{L} 5$ and $\mathrm{L} 7-\mathrm{S} 1:{ }^{*} p<0.05,{ }^{* *} p<0.01,{ }^{* * * *} p<0.001$.

Swing angle at the hip and ankle joints were similar, whereas that for the knee joint was significantly larger $\left(t_{(4)}=\right.$ $-6.21, p=0.002$, unpaired $t$ test) compared with those observed during FW locomotion triggered by ES of L6 (Fig. 4A). The mean values for the Stance angle at the hip and ankle joints were significantly smaller (respectively, $t_{(3)}=7.81, p=$ 0.002 , and $t_{(4)}=3.93, p=0.008$, unpaired $t$ test), whereas that at the knee joint was slightly larger, compared with those observed during FW locomotion triggered by ES of L6 (Fig. 4A).

We also found that during BW, the range over which angles of hindlimb joints changed during the locomotor cycle was significantly smaller $\left(t_{(208)}=12.22\right.$, $p=1.5 \times 10^{-26}$, unpaired $t$ test $)$, and as a result, the paw excursion was significantly shorter $\left(t_{(3)}=2.71, p=0.036\right.$, unpaired $t$ test), compared with those observed during FW locomotion evoked by ES of L6 (Fig. 4C, $B$, respectively). Finally, the stability of the limb locomotor movements was slightly worse, and asymmetry in the step length of the left and right limbs (the coefficient of the asymmetry) was larger compared with those observed during FW locomotion triggered by ES of L6 (Fig. $4 D, E$, respectively). In general, the main characteristics of the BW locomotor pattern were similar to those described earlier for intact (Buford and Smith, 1990; Buford et al., 1990; Zelenin et al., 2011) and decerebrate cats (Musienko et al., 2007, 2012).
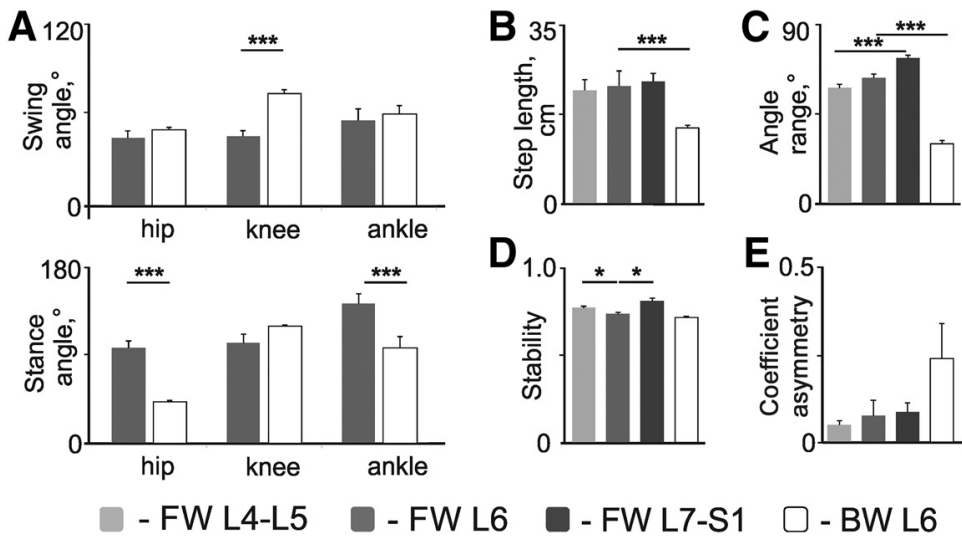

$\mathbf{E}_{0}$

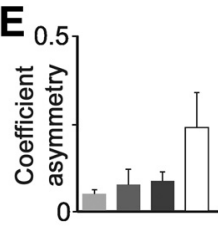

Figure 4. Comparison of kinematic characteristics of FW stepping movements evoked by ES of different lumbosacral segments and BW stepping movements. $A$, Angles of the hindlimb joints at maximal limb flexion during swing (Swing angle) and maximal limb extension during stance (Stance angle). $\boldsymbol{B}$, Step length. $\boldsymbol{C}$, The range of hindlimb joint angles changes during the locomotor cycle (Stance angle - Swing angle, the difference between Stance angle and Swing angle averaged over all hindlimb joints in all cats). $\boldsymbol{D}$, Stability of the limb locomotor pattern (self-similarity coefficient). $\boldsymbol{E}$, Left-right step length asymmetry (coefficient of asymmetry). Kinematic characteristics were averaged over $120 \mathrm{FW}$ locomotor cycles in four cats and over $45 \mathrm{BW}$ locomotor cycles in three cats (mean \pm SE; indication of significance level: ${ }^{*} p<0.05,{ }^{* * *} p<0.001$ ).

\section{Distribution of c-Fos-positive neurons in cats stepping FW} and in cats stepping BW

To compare the distribution of spinal neurons activated by ES during FW and BW locomotion, we used c-Fos immunostaining. We suggested that neurons activated during locomotion contribute to the control of locomotor movements and thus belong to locomotor networks. An example of a microphotograph taken from a single L7 frontal section of the cat Fw2 is shown in Figure $2 B$. The locomotor task (FW locomotion, in this case) produced 
Table 2. Number of FOS + nuclei revealed in L4-S1 segments of individual cats

\begin{tabular}{lrrrrrrr}
\hline & sFW & Fw1 & Fw2 & Fw3 & Bw1 & Bw2 & Bw3 \\
\hline L4 & 52 & 287 & 296 & 301 & 156 & 411 & 423 \\
L5 & 103 & 176 & 365 & 263 & 223 & 341 & 327 \\
L6 & 96 & 315 & 227 & 443 & 361 & 827 & 469 \\
L7 & 116 & 460 & 377 & 479 & 445 & 824 & 828 \\
S1 & 92 & 288 & 526 & 377 & 277 & 509 & 415 \\
Total & 471 & 1526 & 1791 & 1863 & 1462 & 2912 & 2462
\end{tabular}

Asterisk marks the cat (Bw1) that performed asymmetric locomotor movements reflected in the FOS + nuclei distribution. A substantial reduction in the number of FOS + nuclei on the side ipsilateral to the hindlimb exhibited a reduced step length resulted in a relatively small (compared with that observed in other BW stepping cats) total number of FOS + nuclei revealed in this cat.
A

L4
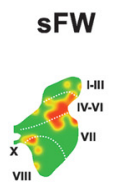

L5

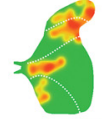

L6

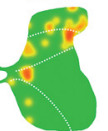

L7

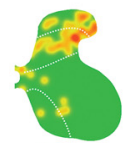

S1

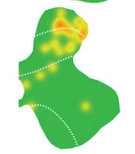

FW

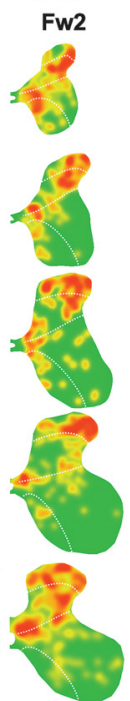

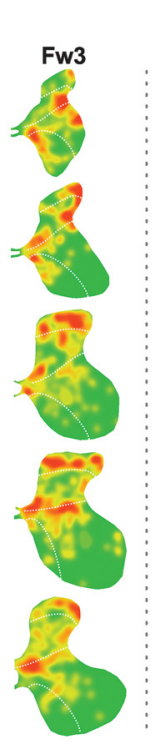

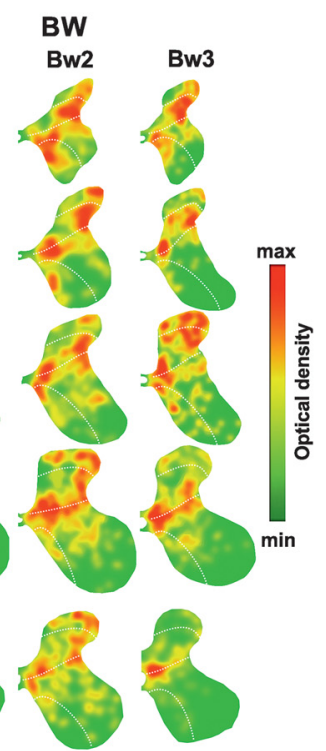

B $\mathrm{L4}$
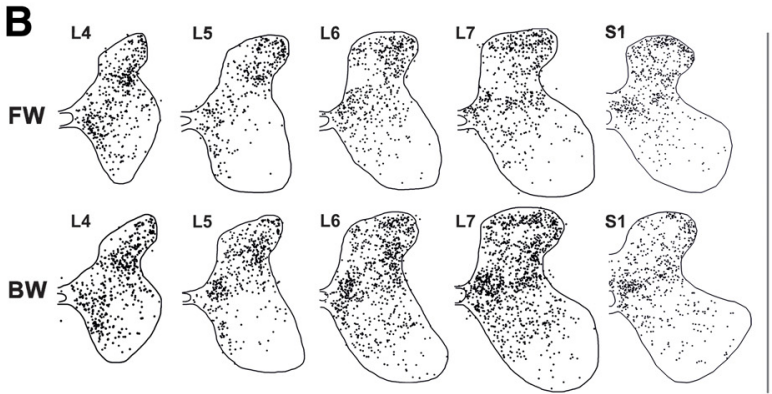

C

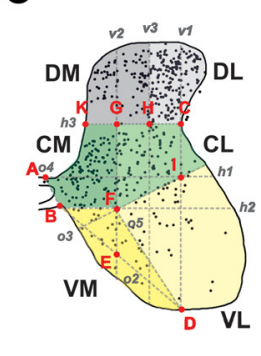
activation.

Figure 5. Distribution of FOS + nuclei across the gray matter in segments $L 4-S 1$ of cats that performed FW and BW locomotion. $A$, Density of the FOS + nuclei distribution across the left half of the gray matter in segments L4-S1 of individual cats. In color-coded images, the green-to-red gradient corresponds to the optical density of the gray level image's loci after the Gaussian blur. This gradient is individual for each segment in each cat. $\boldsymbol{B}$, Distribution of FOS + nuclei across the gray matter in segments L4 -S1 of all cats that performed FW and BW locomotion. For each segment, the image shows the location of all FOS + nuclei in the left half of gray matter combined from 15 sections taken from three cats ( 5 sections from each cat). FW and BW, cats that performed FW and BW locomotion, respectively, for 1.5-2 h. sFW, the cat that performed FW locomotion for 30 min. C, Subdivision of the gray matter into six areas (modified from Matsushita, 1970; see text for explanation). DL, Light gray; DM, dark gray; CL, light green; CM, dark green; VL, light yellow; VM, dark yellow.

clear c-Fos nuclear labeling in numerous cells located in various parts of the gray matter. The majority of labeled neurons in cats that performed FW and BW locomotion were interneurons located in Rexed laminae I-VIII. The FOS + nuclei of interneurons are clearly visible in magnified boxed area 1 in the upper middle part of Figure $2 B$. Solitary large FOS + nuclei (Fig. $2 B$, top right, inset box 2, black arrows) were identified in the lateral region of the ventral horn corresponding to motoneuronal pools. They accounted for $0.97-2.5 \%$ and for $1.19-1.53 \%$ of all FOS + nuclei revealed in individual FW- and BW-stepping cats, respectively.
These large FOS + nuclei presumably belong to motoneurons, because their somata (clearly seen due to cytosolic background immunostaining) were large $\left(2600 \pm 80 \mu \mathrm{m}^{2}\right)$. In the ventral horn, large cells with cytosolic gray staining but with unstained could be seen, suggesting that the motoneuronal FOS + nuclear label was not an artifact. Rare FOS + nuclei observed in the region motoneuronal pools in the present study confirm results obgesting that most motoneurons do not express c-fos after

The number of FOS+ nuclei within segments L4-S1 varied from 1526 to 1863 and from 1462 to 2912 in individual FWand BW-stepping cats, respectively (Table 2). The distribution patterns of FOS + nuclei on the left side of the cross sections of the gray matter in $\mathrm{L} 4-\mathrm{S} 1$ revealed in individual $\mathrm{FW}$ - and BW-stepping cats, as well as in all FW-and in all BW-stepping cats, are shown in Figure 5, $A$ and $B$, respectively. In general, these patterns were similar between FW- and BW-stepping cats. Within the dorsal horn, in all segments, the highest density of FOS+ nuclei was observed in the lateral parts of laminae I-VI, although in segments L6-L7, the medial parts also showed substantial density of FOS + nuclei. Within the intermediate gray matter, in most cases, FOS+ nuclei were unevenly distributed, and two clusters with higher density were evident: (1) around the boundary between laminae VII and X and (2) in a more lateral region. Both clusters occupied areas at the border between laminae VI and VII. Finally, many FOS+ nuclei were revealed within the ventral horn, in laminae VII and VIII.

Thus, areas of high density of FOS+ nuclei were located not within a definite Rexed lamina but rather occupied areas at the borders of two or three laminae or within a particular part of the lamina. For this reason, to quantitatively compare FOS + nuclei distribution on the cross section of the gray matter in animals that performed FW and BW locomotion, we adapted a topographic subdivision of the spinal cord gray matter elaborated by Matsushita (1970). He subdivided the gray matter into 14 areas using several landmarks as key points for vertical, horizontal and oblique lines (Fig. 5C). These key points were the ventral median fissure, the protrusion of the white matter into the lateral gray matter, the most dorsal and ventral surfaces of the pericanal gray matter, and intersection points of these lines. As in the original paper, we drew vertical $(v)$ lines $v 1$ and $v 2$, horizontal $(h)$ lines $h 1$ and $h 2$, and oblique (o) line $o 2$. We excluded line $o 1$ but added lines $v 3, h 3$, 03,04 , and $o 5$ for the most complete coverage of areas with a high density of FOS + nuclei. Thus, as shown in Figure $5 C$, line $v 1$ was drawn parallel to the ventral median fissure through the 
protrusion of the white matter into the lateral gray matter (point C); $v 1$ crossed the ventral border of the gray matter at point D. Lines $h 1$ and $h 2$ were tangents at the dorsal and ventral borders of the pericanal gray matter (points A and B, respectively); line $h 1$ crossed line $v 1$ at point I. Line $o 2$ connected point D with point B; point $\mathrm{E}$ was the midpoint of segment BD. Line $v 2$ was drawn parallel to $v 1$ through point $\mathrm{E}$, and it crossed line $h 2$ at point F. Line $h 3$ was drawn through point $\mathrm{C}$ parallel to lines $h 1$ and $h 2$; $h 3$ crossed line $v 2$ at point G; point $\mathrm{H}$ was the midpoint of segment CG. Line $v 3$ was drawn parallel to $v 1$ and $v 2$ through point $\mathrm{H}$. Lines 03,04 , and $o 5$ were drawn through points I and F, A and $\mathrm{B}$, and $\mathrm{D}$ and $\mathrm{F}$, respectively. As a result, the gray matter was subdivided into six areas: two areas in the dorsal horn [medial dorsal (DM) and lateral dorsal (DL) areas, corresponding to Fig. $5 C$, dark and light gray areas, respectively], two in the ventral horn [medial ventral (VM) and lateral ventral (VL) areas corresponding to Fig. $5 C$, dark and light yellow areas, respectively], and two in the central region [medial central (CM) and lateral central (CL) areas corresponding to Fig. $5 C$, dark and light green areas, respectively].

Figure $6 A$ shows the mean $( \pm \mathrm{SE})$ number of FOS + nuclei in each of the six areas (DL, DM, CL, CM, VL, and VM) of the gray matter in segments L4-S1 of cats that performed FW and BW stepping. It can be seen that in segments L6 and L7, the number of FOS+ nuclei in the CL, $\mathrm{CM}$, and VL areas in cats that performed BW stepping was significantly ( $\sim 2$-fold) higher than that observed in FW-stepping cats (Table 3). In addition, in BWstepping cats, a significantly higher numbers of FOS+ nuclei were also found in the DL and VM areas of segment L6 (Table 3). Thus, the region of the spinal cord (L6-L7) in which ES evoked BW locomotion (Fig. $3 A$ ) contained significantly more neurons activated during BW stepping than during FW stepping. This result could be explained by direct activation of the majority of neurons located under the epidural electrode by electrical current. To test this hypothesis, we compared the number of FOS+ nuclei distribution in two cats, Fw2 and Bw2. These two cats performed locomotion in opposite directions in response to ES of the same segment (L6; Fig. 2A) with similar parameters (196 $\mu \mathrm{A}$ and $219 \mu \mathrm{A}$, respectively). The data shown in Table 2 and Figures $5 A$ and $6 B$ allow the comparison of the distribution of FOS + nuclei along segments L4-S1, as well as in different areas of the gray matter of these spinal segments, in Fw2 and Bw2. It can be seen (Table 2) that the mean number of FOS+ nuclei on the cross section of the segment subjected to ES (L6) was substantially (more than 3-fold) higher in Bw2 than in Fw2. In Bw2, a twofold higher number of FOS + nuclei was also found in L7. The difference in the number of FOS + nuclei in different areas of the gray matter in the L4-S1 segments
Table 3. Areas of grey matter with significant difference in number of c-Fos-positive neurons during FW and BW locomotion

\begin{tabular}{lcccccc}
\hline \multirow{2}{*}{ Segment } & & & & & \multicolumn{3}{c}{ Statistical data } \\
\cline { 5 - 7 } & Zone & FW & BW & df & $z$ & $p$ \\
\hline & DL & 51.8 & 77 & 6 & -3.08 & 0.001 \\
& CL & 22.2 & 45.8 & 6 & -2.07 & 0.019 \\
& CM & 37.5 & 63.2 & 6 & -1.72 & 0.042 \\
& VL & 11.3 & 27.5 & 6 & -1.86 & 0.031 \\
L7 & VM & 9 & 27.3 & 6 & -2.55 & 0.005 \\
& CL & 37.5 & 59.3 & 6 & -1.80 & 0.036 \\
& CM & 38.2 & 95.7 & 6 & -2.87 & 0.002 \\
& VL & 21 & 47.5 & 6 & -2.43 & 0.008 \\
\hline
\end{tabular}

between Fw2 and Bw2 (Fig. 6B) was similar to that observed when the whole group of FW-stepping cats and the whole group of BW-stepping cats were compared (Fig. 6A). In particular, the largest difference was observed in the central (CM and CL) and ventral (VL and VM) areas of L6 and L7. Thus, the quantitative difference in distribution of FOS + nuclei between FW- and BW-stepping cats was related mostly to the direction of performed locomotion and not to the site of the ES. 
A

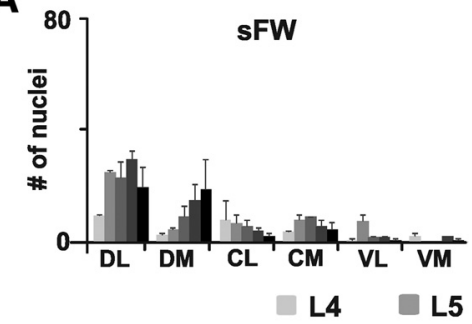

B

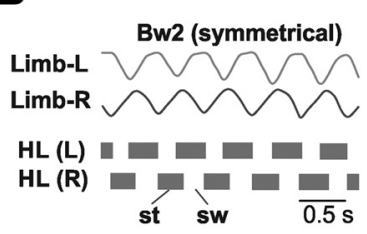

D

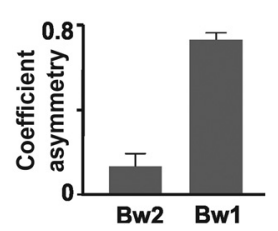

$\mathrm{E}$

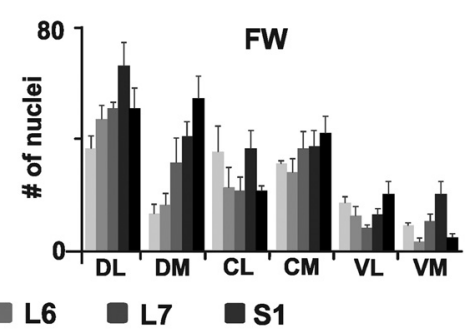

C
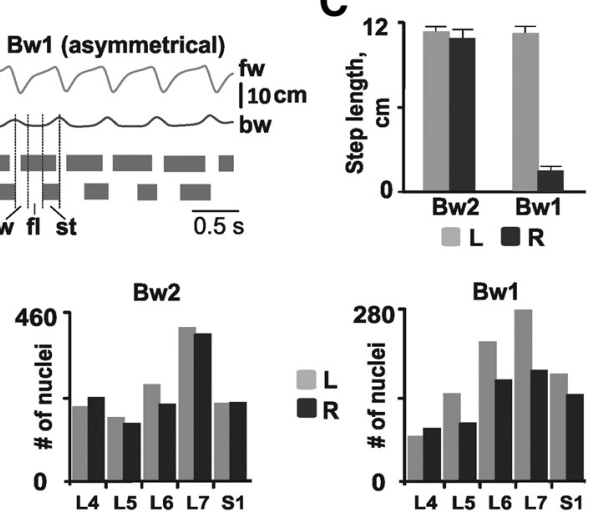

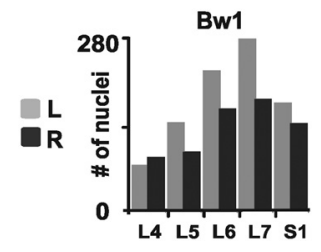

Figure 7. Specificity of c-Fos immunostaining. $A$, The mean numbers ( \pm SE) of FOS + nuclei in the DL, DM, CL, CM, VL, and VM areas of the gray matter in segments $L 4-S 1$ of the cat (sFW) that performed a short period of stepping (30 min) and in cats (FW) that performed long-lasting stepping $(1.5-2 \mathrm{~h})$. For the cat sFW, an average based on five sections from each segment is presented. For FW cats, an average based on 15 sections from each segment taken from three cats ( 5 sections from each segment of each individual cat) is presented. $\boldsymbol{B}-\boldsymbol{E}$, Kinematics of locomotor movements $(\boldsymbol{B}, \boldsymbol{C})$ and distribution of FOS + nuclei $(\boldsymbol{D}, \boldsymbol{E})$ in two cats that performed symmetrical and asymmetrical walking (Bw2 and Bw1, respectively). $\boldsymbol{B}$, Recording of locomotor movements of the right and left limbs (Limb-R and Limb-L) in Bw2 and Bw1. sw, Swing; st, stance; $\mathrm{fl}$, a part of the locomotor cycle when the flexed limb is maintained above the surface at the extreme posterior position (relative to the trunk) before landing. $C$, Mean ( $\pm S E$ ) of the step length $(n=50)$ exhibited by the left (L; light gray) and right (R; dark gray) hindlimb of Bw2 and Bw1. D, The coefficient of asymmetry (mean \pm SE) between the left and right hindlimbs in BW2 and Bw1. $E$, The number of F0S + nuclei on the left (L; light gray) and right ( $R$; dark gray) sides of segments $L 4-S 1$ revealed in Bw2 and Bw1. The total number of FOS + nuclei in five sections from each segment is shown.

\section{Specificity of c-Fos immunostaining}

To prove the specificity of c-Fos immunostaining in our experiments, we first compared the distribution of FOS + nuclei in a single cat $(\mathrm{sFW})$ stepping $\mathrm{FW}$ for a short period $(30 \mathrm{~min})$ with that revealed in cats (Fw1, Fw2, and Fw3) stepping FW for a long period (1.5-2 h). Second, we compared the distributions of FOS+ nuclei in two cats, Bw1 and Bw2, that performed asymmetrical and symmetrical BW stepping, respectively.

In sFW, we found early recruited FOS + neurons (Ahn et al., 2006). The total number of FOS + nuclei within the segments L4-S1 in this cat was substantially lower than that in individual cats that performed long periods of FW stepping (471 against 1526-1863, respectively; Table 2). The patterns of FOS + nucleus density over the cross section of the gray matter in segments L4-S1 were similar between sFW and individual cats that performed long-lasting FW stepping ( Fig. 5A, compare sFW with Fw1, Fw2, Fw3). As in the cats that performed long periods of FW stepping, in sFW, the highest density of FOS + nuclei was observed in the lateral part of the dorsal horns (DL area), at laminae VI, VII and X boundaries (CM and $\mathrm{CL}$ areas), and within the medial part of the ventral horn (VM area). Thus, after a short episode of FW stepping $(30 \mathrm{~min})$, $c$-fos was activated within the same areas of the gray matter in which it was strongly expressed after a long period of FW stepping (1.5-2 h). However, the number of FOS+ nuclei within each of these areas was considerably lower in sFW com- pared with the mean number of FOS+ nuclei observed in the cats that performed long-lasting stepping (Fig. 7A, compare $\mathrm{sFW}$ and $\mathrm{FW}$ ).

To further test the specificity of c-Fos immunostaining in our experiments, we addressed the question of whether the distribution of FOS + nuclei in the spinal cord depends on the kinematics of locomotor movements. For this purpose, we compared the distribution of FOS + nuclei in the right and left parts of the L4-S1 segments in two cats, Bw2 and Bw1, that performed symmetrical and asymmetrical stepping, respectively (Fig. 7B). In Bw1, the locomotor asymmetry was caused by a $1 \mathrm{~mm}$ displacement of the ES electrode from the midline to the left (Fig. 2A), which resulted in impairment of locomotor movements of the contralateral (right) hindlimb: shortening of the stance phase (Fig. $7 B, B w 1$, st) and prolongation of the part of the locomotor cycle during which the limb was maintained above the surface. This part of the cycle consisted of a swing phase (movement of the limb from anterior to posterior extreme position relative to the trunk) and a period when the limb with flexed configuration was maintained in this posterior position during $0.1-0.2 \mathrm{~s}$ (Fig. 7B, Bw1, sw and fl, respectively) before the limb landing started. Bw1 showed a dramatic decrease in the step length of the right limb compared with that of the left limb (Fig. 7C, Bw1). Note that the step length was similar in both hindlimbs of Bw2 (Fig. 7C, Bw2). Because the amplitude of the horizontal component of the BW step exhibited by the right hindlimb in Bw1 was dramatically smaller than that performed by the left hindlimb, one can expect that the number of neurons in the network generating the BW component of the step on the right side of the spinal cord in Bwl would be smaller than that on the left side.

Figure $7 E$ shows the numbers of FOS + nuclei on the left and right sides in segments $\mathrm{L} 4-\mathrm{S} 1$ of $\mathrm{Bw} 2$ and Bw1. It can be seen that in the symmetrically stepping cat (Bw2; Fig. $7 B-D)$, the numbers of FOS + nuclei were similar between the two sides of the spinal cord in all segments. In contrast, in the asymmetrically stepping cat (Bw1), there were substantially fewer FOS + nuclei on the right side in segments L5-S1 than on the left side. The most prominent (1.5- to 2-fold) difference was observed within the regions DM and CM (Fig. 7E). Thus, the distribution of FOS+ nuclei in the spinal cord depended on the kinematics of locomotor movements.

Together, the obtained results suggest that c-Fos immunostaining in our experiments was specific, i.e., c-Fos-labeled neurons belonged to locomotor networks.

\section{Discussion}

In the present study on decerebrate cats, we compared, first, the efficacy of ES stimulation of different segments of the lumbosacral enlargement to evoke FW and BW locomotion 
and, second, the distribution of spinal networks generating $\mathrm{FW}$ and $\mathrm{BW}$ locomotion.

Epidural stimulation of the spinal cord can immediately activate spinal locomotor networks, as demonstrated in spinal animals (Barthélemy et al., 2007; Courtine et al., 2009) and humans (Dimitrijevic et al., 1998; Shapkov and Shapkova, 1998). It has been suggested that ES effects are based on stimulation of myelinated sensory fibers of dorsal roots, resulting in polysynaptic activation of spinal locomotor networks (Capogrosso et al., 2013).

In the present study, we found that in each animal, ES sites that evoked both FW and BW locomotion were located in a narrow zone (usually within the L6 segment, but in some animals from caudal L5 to caudal L7). Epidural stimulation of other segments within the L3-S2 region evoked FW locomotion only during BW treadmill motion and did not evoke any rhythmic limb movements during FW treadmill motion. Thus, a relatively small group of afferent fibers activated by ES at any segment from L3 to S2 is able to activate networks generating $\mathrm{FW}$ locomotion. In contrast, networks generating BW locomotion can be activated only by afferents excited by ES applied near and at L6-L7.

A possible explanation for this result could be a difference in the rostrocaudal distribution of corresponding locomotor networks [i.e., a wide (within L3-S2) and a narrow (within L6-L7) distribution, respectively].

To test this hypothesis, we compared the distribution of spinal neurons activated during FW and BW stepping using c-Fos immunostaining. Earlier, this technique was used to study the distribution of spinal neurons activated during FW locomotion (Dai et al., 2005; Ahn et al., 2006; Ichiyama et al., 2008; Noga et al., 2009). It should be noted that some neurons, despite being activated, do not show c-Fos elevation (Hunt et al., 1987; Dragunow and Faull, 1989). Thus, it is possible that only a subset of the neurons forming spinal locomotor networks was revealed in the present study. It is also likely that some of the c-Fos-labeled neurons were related to activation of the locomotor networks and did not contribute to the generation of locomotor movements. However, our recent study has shown that the majority of spinal neurons activated by ES exhibit rhythmic activity, suggesting that they contribute to the generation of locomotion (Zelenin et al., 2015, 2016). The distribution of c-Fos-labeled neurons revealed in the present study reflected differences in the kinematics of locomotor movements [small and large paw excursion (Fig. $7 B-$ E), FW and BW stepping (Fig. 6)] and was similar to that observed in cats performing locomotion in earlier studies (Dai et al.,
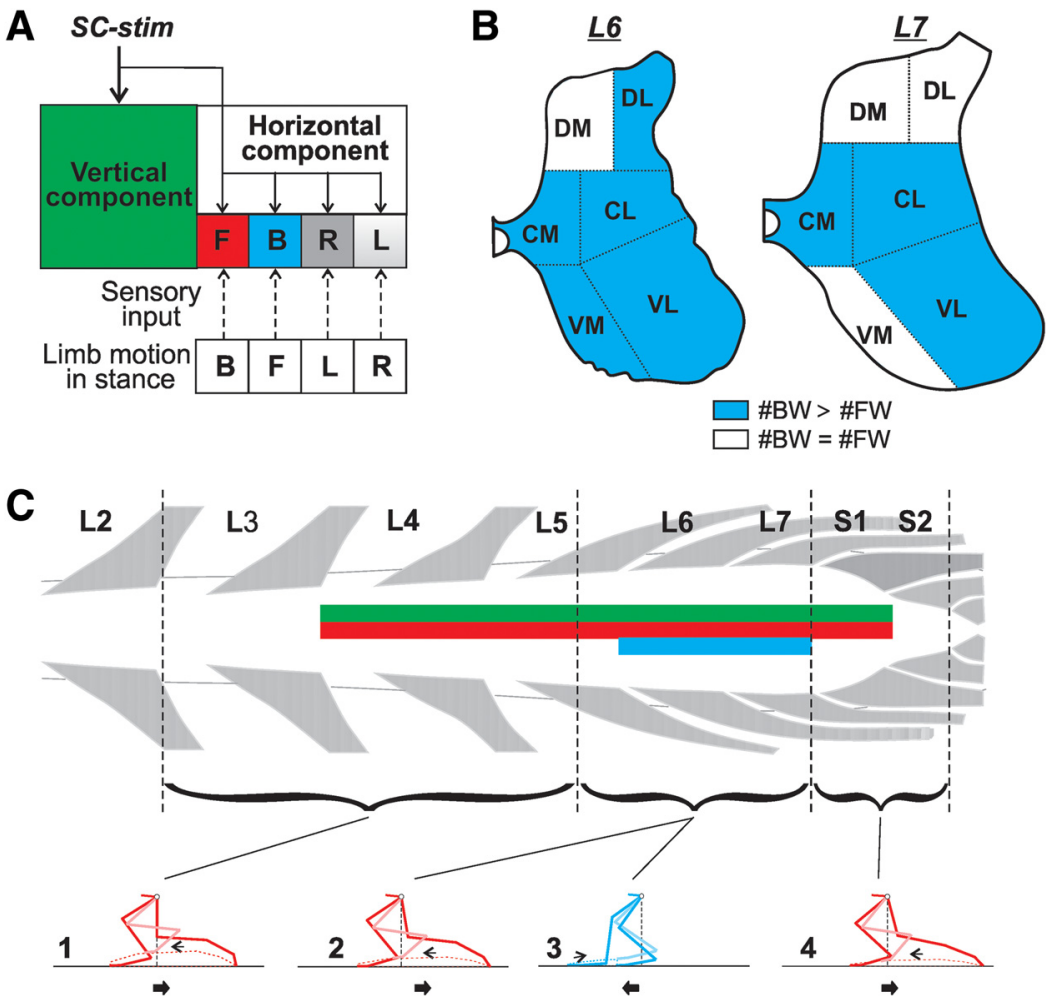

Figure 8. Distribution of spinal networks generating FW and BW stepping. A, A hypothesis about the control of step direction (modified from Musienko et al., 2012). The locomotor system includes two principal mechanisms, one generating transfer from one extreme point to the other). The latter includes networks generating the horizontal component of step in ifferent directions (for simplicity, only the networks generating steps in four directions are shown: F, forward; B, backxtreme position triggers a limb transfer. ES of the spinal cord activates a network generating a vertical component of the step. It also causes subthreshold activation of all networks generating a horizontal component. Due to the treadmill motion which will evoke the BW step. Thus, ES stimulation can evoke stepping opposite to the direction of treadmill motion. $\boldsymbol{B}$, Areas of the gray matter in $L 6$ and $L 7$ where the neurons of the network generating the horizontal component of BW steps (marked in blue). Abbreviations are as in Figure 5C. C, A scheme for the rostrocaudal distribution of a network steps (red thick line) and a network generating the horizontal component for BW steps (blue thick line) in the lumbosacral rgement. Insets 1-4, Hindlimb configurations in the middle of swing (pink and light blue) and at extreme limb the directions of the limb swing movement, respectively. ES of rostral (L4-L5) and caudal (S1-S2) segments containing component of the step, the horizontal component for the FW step and the horizontal component for the BW step), depending on the direction of the treadmill belt motion, evokes FW (inset 2) or BW (inset 3) stepping, respectively. Note that FW-stepping movements evoked by ES of rostral segments are performed at a more rostral position in relation to the trunk and with more flexed limb compared with those evoked by ES of caudal segments (compare insets 1 and 4).

2005; Noga et al., 2009). These findings allow us to suggest that the majority of c-Fos-labeled neurons revealed in the present study belong to locomotor networks.

Surprisingly, we found that qualitatively, the distribution of FOS + nuclei was similar in cats stepping FW and BW. In both groups of cats, FOS + nuclei were found within L4-S1 spinal segments. In both groups, the density of FOS + nuclei was higher in three regions of the gray matter: (1) in the lateral parts of laminae I-VI in the dorsal horn (DL area), (2) in the intermediate gray matter, at boundaries between laminae VI and VII (CL area), as well as between laminae VII and X (CM area), and (3) in the ventromedial region, including lamina VIII (VM area). A similar rostrocaudal distributions of FOS + nuclei and patterns of FOS+ 
nucleus density over the cross section of the gray matter were observed in cats performing MLR-evoked FW locomotion (Dai et al., 2005). This is in line with our recent results. We found that the same spinal neurons are rhythmically activated during FW locomotion evoked by MLR stimulation and by ES of the spinal cord (Zelenin et al., 2015). We have also shown that interneurons that were rhythmically active during ES-evoked FW and BW locomotion were located in all areas of the gray matter in L4-L6 (Zelenin et al., 2016).

Most likely, the majority of c-Fos-labeled cells located in the DL and DM areas were activated by sensory feedback from the moving limb, since in cats performing fictive locomotion, their number is dramatically decreased (Carr et al., 1995; Dai et al., 2005). c-Fos-labeled neurons located in the CL and CM areas may include Ia inhibitory interneurons, midlumbar group II interneurons, and neurons of ascending tracts (i.e., spinocerebellar and spinoreticular tracts). It has been shown that all these neurons are rhythmically active during MLRevoked FW locomotion (Feldman and Orlovsky, 1975; McCrea et al., 1980; Noga et al., 1987; Pratt and Jordan, 1987; Shefchyk et al., 1990; Stecina et al., 2013; Arshavsky et al., 1972a,b). c-Fos-labeled neurons in the CM area may include commissural interneurons contributing to left-right limb alternation during locomotion (Kjaerulff and Kiehn, 1996; Kiehn and Butt, 2003; Matsuyama et al., 2004).

Although the distributions of FOS + nuclei in the lumbosacral enlargement were qualitatively similar between cats that performed FW and BW locomotion, they differed quantitatively. The number of c-Fos-labeled neurons in specific areas of the gray matter in the L6 and L7 segments of cats performing BW locomotion (Fig. $8 B$, blue) was significantly higher than that observed in cats performing FW stepping. We demonstrated that, first, the higher number of labeled neurons in BW-stepping cats was not a result of nonspecific activation of neurons located under the epidural electrode (Fig. 6B). Second, the number of labeled neurons in BW-stepping cats correlated with the amplitude of the horizontal component of BW steps (Fig. $7 B-E$ ). These results suggest that the higher number of labeled neurons in BW-stepping cats compared with that observed in FWstepping cats reflects activation of a specific network generating the BW direction of stepping.

We found that the kinematics of the hindlimb FW-stepping movements depended on the rostrocaudal position of the epidural electrode. During FW stepping evoked by ES of rostral segments, the limb configuration was more flexed than that during stepping evoked by ES of caudal segments (Fig. 8C, compare insets 1 and 4), suggesting predominance in the activity of flexors and extensors, respectively. Because in rostral and caudal segments of the lumbosacral enlargement, motoneuronal pools for flexor and extensor muscles prevail, respectively (Vanderhorst and Holstege, 1997), one can suggest that ES of a specific segment not only activates locomotor networks generating FW locomotion but also increases the excitability level of motoneurons located in stimulated and neighboring segments.

The main kinematical difference of BW locomotion from FW locomotion is reversed hip joint motion: flexion (not extension) during stance and extension (not flexion) during swing (Buford et al., 1990). One of the important afferent signals contributing to triggering the FW swing is activation of muscle spindle afferents of hip flexors at the end of the stance (Rossignol et al., 2006). One can suggest that during BW locomotion, the afferent signals about hip flexion (from muscle spindle afferents of hip extensors) at the end of the stance could be used for triggering the BW swing. Thus, motoneuronal pools of hip extensors and afferents from them could represent important elements of the network determining the horizontal component of the BW step. Segments L6-L7, whose stimulation evokes BW walking, contain these elements (Hamm et al., 1985; Vanderhorst and Holstege, 1997).

Earlier (Musienko et al., 2012), we proposed a hypothesis about the control of step direction (Fig. 8A). We proposed that the locomotor system includes two principal mechanisms, one generating the vertical component of the step (limb elevation and lowering) and the other generating the horizontal component (limb transfer from one extreme point to the other). The latter includes networks generating the horizontal component of the step in different directions (Fig. 8A, see legend). In the framework of the two-layered locomotor CPG model (Rybak et al., 2015), it can be suggested that the vertical-component mechanism includes the rhythm generator and a part of the pattern-formation layer, while the horizontal-component networks belong to the pattern-formation layer.

To conclude, we suggest that networks generating the vertical component of steps and the horizontal component for FW stepping are distributed throughout the whole lumbosacral enlargement (Fig. $8 C$, green and red lines, respectively). By contrast, the network generating the horizontal component for BW stepping is located in L6-L7 only (Fig. 8C, blue line). Thus, to activate this network, ES should be applied near the L6-L7 segments, whereas widely distributed networks generating vertical and horizontal components of FW stepping can be activated by ES of any of the L3-S2 segments. To evoke both FW and BW stepping, the same widely distributed network generating the vertical component of the step should be activated. This can explain the qualitatively similar distribution of c-Fos-labeled neurons in FW- and BWstepping cats. Because neurons of the network generating the horizontal component for FW stepping (FW neurons) are widely distributed in the lumbosacral enlargement, whereas all neurons of the network generating the horizontal component for BW stepping (BW neurons) are concentrated in L6-L7, the number of BW neurons in L6-L7 is substantially higher than that of FW neurons.

\section{References}

Ahn SN, Guu JJ, Tobin AJ, Edgerton VR, Tillakaratne NJ (2006) Use of c-fos to identify activity-dependent spinal neurons after stepping in intact adult rats. Spinal Cord 44:547-559. CrossRef Medline

Arshavsky YI, Berkinblit MB, Gelfand IM, Orlovsky GN, Fukson OI (1972a) Recordings of neurons of the dorsal spinocerebellar tract during evoked locomotion. Brain Res 43:272-275. CrossRef Medline

Arshavsky YI, Berkinblit MB, Gelfand IM, Orlovsky GN, Fukson OI (1972b) Origin of modulation of the ventral spinocerebellar tract during locomotion. Brain Res 43:276-279. CrossRef Medline

Arshavsky YI, Gelfand IM, Orlovsky GN (1986) Cerebellum and rhythmical movements. New York: Springer.

Barthélemy D, Leblond H, Rossignol S (2007) Characteristics of mechanisms of locomotion induced by intraspinal microstimulation and dorsal root stimulation in spinal cats. J Neurophysiol 97:1986-2000. CrossRef Medline

Beloozerova IN, Zelenin PV, Popova LB, Orlovsky GN, Grillner S, Deliagina TG (2003) Postural control in the rabbit maintaining balance on the tilting platform. J Neurophysiol 90:3783-3793. CrossRef Medline

Buford JA, Smith JL (1990) Adaptive control for backward quadrupedal walking: II. hindlimb muscle synergies. J Neurophysiol 64:756-766. CrossRef Medline

Buford JA, Zernicke RF, Smith JL (1990) Adaptive control for backward quadrupedal walking: I. posture and hindlimb kinematics. J Neurophysiol 64:745-755. CrossRef Medline

Capogrosso M, Wenger N, Raspopovic S, Musienko P, Beauparlant J, Bassi 
Luciani L, Courtine G, Micera S (2013) A computational model for epidural electrical stimulation of spinal sensorimotor circuits. J Neurosci 33:19326-19340. CrossRef Medline

Carr PA, Huang A, Noga BR, Jordan LM (1995) Cytochemical characteristics of cat spinal neurons activated during fictive locomotion. Brain Res Bull 37:213-218. CrossRef Medline

Cazalets JR, Borde M, Clarac F (1995) Localization and organization of the central pattern generator for hindlimb locomotion in newborn rat. J Neurosci 15:4943-4951. CrossRef Medline

Courtine G, Gerasimenko Y, van den Brand R, Yew A, Musienko P, Zhong H, Song B, Ao Y, Ichiyama RM, Lavrov I, Roy RR, Sofroniew MV, Edgerton VR (2009) Transformation of nonfunctional spinal circuits into functional states after the loss of brain input. Nat Neurosci 12:1333-1342. CrossRef Medline

Dai X, Noga BR, Douglas JR, Jordan LM (2005) Localisation of spinal neurons activated during locomotion using the $\mathrm{c}$-fos immunohistochemical method. J Neurophysiol 93:3442-3452. CrossRef Medline

Dimitrijevic MR, Gerasimenko Y, Pinter MM (1998) Evidence for a spinal central pattern generator in humans. Ann N Y Acad Sci 860:360-376. CrossRef Medline

Dragunow M, Faull R (1989) The use of c-fos as a metabolic marker in neuronal pathway tracing. J Neurosci Methods 29:261-265. CrossRef Medline

Feldman AG, Orlovsky GN (1975) Activity of interneurons mediating reciprocal Ia inhibition during locomotion. Brain Res 84:181-194. CrossRef Medline

Gerasimenko Y, Musienko P, Bogacheva I, Moshonkina T, Savochin A, Lavrov I, Roy RR, Edgerton VR (2009) Propriospinal bypass of the serotonergic system that can facilitate stepping. J Neurosci 29:5681-5689. CrossRef Medline

Grillner S (1975) Locomotion in vertebrates: central mechanisms and reflex interaction. Physiol Rev 55:247-304. CrossRef Medline

Grillner S, Zangger P (1979) On the central generation of locomotion in the low spinal cat. Exp Brain Res 34:241-261. Medline

Grillner S, Zangger P (1984) The effect of dorsal root transection on the efferent motor pattern in the cat's hindlimb during locomotion. Acta Physiol 120:393-405. CrossRef Medline

Hamm TM, Koehler W, Stuart DG, Vanden Noven S (1985) Partitioning of monosynaptic Ia excitatory post-synaptic potentials in the motor nucleus of the cat semimembranosus muscle. J Physiol 369:379-398. CrossRef Medline

Hsu LJ, Zelenin PV, Lyalka VF, Vemula MG, Orlovsky GN, Deliagina TG (2017) Neural mechanisms of single corrective steps evoked in the standing rabbit. Neuroscience 347:85-102. CrossRef Medline

Hunt SP, Pini A, Evan G (1987) Induction of c-fos-like protein in spinal cord neurons following sensory stimulation. Nature 328:632-634. CrossRef Medline

Ichiyama RM, Courtine G, Gerasimenko YP, Yang GJ, van den Brand R, Lavrov IA, Zhong H, Roy RR, Edgerton VR (2008) Step training reinforces specific spinal locomotor circuitry in adult spinal rats. J Neurosci 28:7370-7375. CrossRef Medline

Iwahara T, Atsuta Y, Garcia-Rill E, Skinner RD (1992) Spinal cord stimulation-induced locomotion in adult cat. Brain Res Bull 28:99-105. CrossRef Medline

Jasmin L, Gogas KR, Ahlgren SC, Levine JD, Basbaum AI (1994) Walking evokes a distinctive pattern of fos-like immunoreactivity in the caudal brainstem and spinal cord of the rat. Neuroscience 58:275-286. CrossRef Medline

Karayannidou A, Zelenin PV, Orlovsky GN, Sirota MG, Beloozerova IN, Deliagina TG (2009) Maintenance of lateral stability during standing and walking in the cat. J Neurophysiol 101:8-19. CrossRef Medline

Kiehn O (2006) Locomotor circuits in the mammalian spinal cord. Annu Rev Neurosci 29:279-306. CrossRef Medline

Kiehn O, Butt SJ (2003) Physiological, anatomical and genetic identification of CPG neurons in the developing mammalian spinal cord. Prog Neurobiol 70:347-361. CrossRef Medline

Kim SA, Heinze KG, Schwille P (2007) Fluorescence correlation spectroscopy in living cells. Nat Methods 4:963-973. CrossRef Medline

Kjaerulff O, Kiehn O (1996) Distribution of networks generating and coordinating locomotor activity in the neonatal rat spinal cord in vitro: a lesion study. J Neurosci 16:5777-5794. CrossRef Medline

Langlet C, Leblond H, Rossignol S (2005) Mid-lumbar segments are needed for the expression of locomotion in chronic spinal cats. J Neurophysiol 93:2474-2488. CrossRef Medline

Matsushita M (1970) Dendritic organization of the ventral spinal gray matter in the cat. Acta Anat (Basel) 76:263-288. CrossRef Medline

Matsuyama K, Nakajima K, Mori F, Aoki M, Mori S (2004) Lumbar commissural interneurons with reticulospinal inputs in the cat: morphology and discharge patterns during fictive locomotion. J Comp Neurol 474: 546-561. CrossRef Medline

McCrea DA, Rybak IA (2008) Organization of mammalian locomotor rhythm and pattern generation. Brain Res Rev 57:134-146. CrossRef Medline

McCrea DA, Pratt CA, Jordan LM (1980) Renshaw cell activity and recurrent effects on motoneurons during fictive locomotion. J Neurophysiol 44:475-488. CrossRef Medline

Morgan JI, Curran T (1989) Stimulus transcription coupling in neurons: role of cellular immesiate-early genes. Trends Neurosci 12:459-462. CrossRef Medline

Musienko PE, Bogacheva IN, Gerasimenko YP (2007) Significance of peripheral feedback in the generation of stepping movements during epidural stimulation of the spinal cord. Neurosci Behav Physiol 37:181-190. CrossRef Medline

Musienko PE, Zelenin PV, Lyalka VF, Gerasimenko YP, Orlovsky GN, Deliagina TG (2012) Spinal and supraspinal control of the direction of stepping during locomotion. J Neurosci 32:17442-17453. CrossRef Medline

Musienko PE, Deliagina TG, Gerasimenko YP, Orlovsky GN, Zelenin PV (2014) Limb and trunk mechanisms for balance control during locomotion in quadrupeds. J Neurosci 34:5704-5716. CrossRef Medline

Noga BR, Shefchyk SJ, Jamal J, Jordan LM (1987) The role of renshaw cells in locomotion: antagonism of their excitation from motor axon collaterals with intravenous mecamylamine. Exp Brain Res 66:99-105. Medline

Noga BR, Johnson DM, Riesgo MI, Pinzon A (2009) Locomotor-activated neurons of the cat: I. serotonergic innervation and co-localization of 5- $\mathrm{HT}_{7}, 5-\mathrm{HT}_{2 \mathrm{~A}}$, and 5- $\mathrm{HT}_{1 \mathrm{~A}}$ receptors in the thoraco-lumbar spinal cord. J Neurophysiol 102:1560-1576. CrossRef Medline

Orlovsky GN, Deliagina TG, Grillner S (1999) Neuronal control of locomotion: from mollusc to man. Oxford, UK: Oxford UP.

Perell KL, Gregor RJ, Buford JA, Smith JL (1993) Adaptive control for backward quadrupedal walking: IV. Hindlimb kinetics during stance and swing. J Neurophysiol 70:2226-2240. CrossRef Medline

Pratt CA, Jordan LM (1987) Ia inhibitory interneurons and Renshaw cells as contributors to the spinal mechanisms of fictive locomotion. J Neurophysiol 57:56-71. CrossRef Medline

Pratt CA, Buford JA, Smith JL (1996) Adaptive control for backward quadrupedal walking $\mathrm{V}$. mutable activation of bifunctional thigh muscles. J Neurophysiol 75:832-842. CrossRef Medline

Rexed B (1954) A cytoarchitectonic atlas of the spinal cord in the cat. J Comp Neurol 100:297-379. CrossRef Medline

Rossignol S (1996) Neuronal control of stereotypic limb movements. In: Handbook of physiology (Rowell LB, Sheperd JT, eds.), pp 173-216. New York, NY: Oxford UP.

Rossignol S, Bouyer L, Barthélemy D, Langlet C, Leblond H (2002) Recovery of locomotion in the cat following spinal cord lesions. Brain Res Rev 40:257-266. CrossRef Medline

Rossignol S, Dubuc R, Gossard JP (2006) Dynamic sensorimotor interactions in locomotion. Physiol Rev 86:89-154. CrossRef Medline

Rybak IA, Dougherty KJ, Shevtsova NA (2015) Organization of the mammalian locomotor CPG: review of computational model and circuit architectures based on genetically identified spinal interneurons $(1,2,3)$. eNeuro 2:ENEURO.0069-15.2015. CrossRef Medline

Sagar SM, Sharp FR, Curran T (1988) Expression of c-fos protein in brain: methabolic mapping at the cellular level. Science 240:1328-1331. CrossRef Medline

Schindelin J, Arganda-Carreras I, Frise E, Kaynig V, Longair M, Pietzsch T, Preibisch S, Rueden C, Saalfeld S, Schmid B, Tinevez JY, White DJ, Hartenstein V, Eliceiri K, Tomancak P, Cardona A (2012) Fiji: an opensource platform for biological-image analysis. Nat Methods 9:676-682. CrossRef Medline

Shapkov IuT, Shapkova EIu (1998) Spinal locomotor generators in humans: problems in assessing effectiveness of stimulations [in Russian]. Med Tekh 4:24-27. Medline

Shefchyk SJ, McCrea DA, Kriellaars DJ, Fortier PA, Jordan LM (1990) Activity of interneurons within the L4 spinal segment of the cat during 
brainstem-evoked fictive locomotion. Exp Brain Res 80:290-295. Medline

Sherrington CS (1906) The integrative action of the nervous system. New Haven, England: Yale UP.

Shik ML, Orlovsky GN (1976) Neurophysiology of locomotor automatism. Physiol Rev 56:465-501. CrossRef Medline

Stecina K, Fedirchuk B, Hultborn H (2013) Information to cerebellum on spinal motor networks mediated by the dorsal spinocerebellar tract. J Physiol 591:5433-5443. CrossRef Medline

Stein PSG, Mortin LI, Robertson GA (1986) The forms of a task and their blends. In: Neurobiology of vertebrate locomotion (Grillner, ed), pp 201216. London: Macmillan.

Vanderhorst VG, Holstege G (1997) Organization of lumbosacral mo- toneuronal cell groups innervating hindlimb, pelvic floor, and axial muscles in the cat. J Comp Neurol 382:46-76. CrossRef Medline

Zelenin PV, Deliagina TG, Orlovsky GN, Karayannidou A, Stout EE, Sirota MG, Beloozerova IN (2011) Activity of motor cortex neurons during backward locomotion. J Neurophysiol 105:2698-2714. CrossRef Medline

Zelenin PV, Musienko PE, Gorskii OV, Lyalka VF, Gerasimenko YP, Orlovsky GN, Deliagina TG (2015) Activity of individual spinal neurons during locomotion initiated from brainstem and from spinal cord. Soc Neurosci Abstr 41:798.11.

Zelenin PV, Musienko PE, Gorskii OV, Lyalka VF, Merkulyeva N, Gerasimenko YP, Orlovsky GN, Deliagina TG (2016) Activity of individual spinal neurons during forward and backward locomotion. Soc Neurosci Abstr 42:535.02. 